\title{
Evidence-Based PET for Head and Neck Tumours
}

\author{
Gaetano Paone
}

\subsection{Introduction}

Head and neck cancer (HNC) accounts for approximately $5 \%$ of all malignant tumours with a continuous growing incidence. Head and neck squamous cell carcinoma (HNSCC) represents the majority of HNC $[1,2]$. Nodal involvement is frequent in HNC patients, whereas distant metastases are rather uncommon at the time of initial diagnosis and are found approximately in $10 \%$ of patients. There is a clear association with lifestyle and factors as alcoholism, smoking, alimentary factors and viruses for the etiological role, while increasing $\mathrm{T}$ and $\mathrm{N}$ stages remain the most important adverse prognostic factor [3, 4]. Diagnosis of HNC is usually achieved clinically with endoscopy to obtain direct tissue biopsies. Conventional Imaging (CI), including ultrasound (US), computed tomography (CT) and magnetic resonance imaging (MRI) is important for the evaluation of local extension and to provide information about infiltration, involvement of surrounding structures and regional nodal involvement. There is growing evidence, however, that these modalities have limitations for the diagnostic accuracy of nodal involvement and distant metastases. ${ }^{18} \mathrm{~F}-\mathrm{FDG}$ PET/CT, allowing

\section{G. Paone $(\bowtie)$}

Clinic of Nuclear Medicine and Molecular Imaging, Imaging Institute of Southern Switzerland, Ente Ospedaliero Cantonale, Bellinzona, Switzerland e-mail: gaetano.paone@eoc.ch the analysis of both metabolic and anatomic features, is a very useful imaging tool in $\mathrm{HNC}$, in particular for disease staging, detection of carcinoma of unknown primary (CUP), treatment monitoring, evaluation of residual or recurrent disease and for prognostic information [5-7].

\subsection{Staging}

Accurate staging of disease extension at the time of diagnosis is the most important factor for treatment planning and patients prognosis. Furthermore, providing information in early stage of disease is extremely useful for selecting high-risk patients with impact on specifictreatment selection.

\subsubsection{T Staging}

${ }^{18}$ F-FDG PET/CT has high accuracy in detecting the primary tumour but a moderate diagnostic performance than CI to identify the real tumour extension and infiltration of surrounding tissue and structures. These data are necessary for adequate therapeutic strategy and patient prognosis. False-negative results occur on ${ }^{18} \mathrm{~F}$-FDG PET/CT when the primary tumour is superficial or small, but also in areas of high physiologic activity such as in pharyngeal lymphoid tissue. False-positive results of ${ }^{18} \mathrm{~F}$-FDG $\mathrm{PET} / \mathrm{CT}$ may be due to 
inflammatory processes. In literature, we found conflicting data; preliminary studies have shown divergent results of ${ }^{18} \mathrm{~F}$-FDG PET/CT in diagnosis and staging of HNSCC. Rohde et al. compared the diagnostic accuracy of ${ }^{18} \mathrm{~F}-\mathrm{FDG}$ PET/ CT for diagnosing HNSCC in comparison with standard CI showing a pooled sensitivity of $89.3 \%$ and specificity of $89.5 \%$ for ${ }^{18} \mathrm{~F}$-FDG $\mathrm{PET} / \mathrm{CT}$ and a pooled sensitivity and specificity of $71.6 \%$ and $78.0 \%$, respectively, for CI. The authors concluded that ${ }^{18} \mathrm{~F}-\mathrm{FDG}$ PET/CT is highly accurate in diagnosing patients suffering from HNSCC [8]. Chen et al. compared MRI, $\mathrm{CT}$ and ${ }^{18} \mathrm{~F}-\mathrm{FDG} \mathrm{PET} / \mathrm{CT}$ in the diagnosis of local and metastatic nasopharyngeal carcinomas. Their analysis suggested that MRI has good accuracy in diagnosis of $\mathrm{T}$ stage, whereas $\mathrm{CT}$ has a good performance in diagnosis of $\mathrm{N}$ stage and ${ }^{18} \mathrm{~F}$-FDG PET/CT shows a good accuracy in diagnosis of $M$ stage [9]. Similarly for evaluation of extracapsular spread (ECS), CT and MRI may be similarly effective, whereas evidence was lacking for ${ }^{18} \mathrm{~F}$-FDG PET/CT and US [10]. ${ }^{18} \mathrm{~F}-\mathrm{FDG}$ PET/CT can provide, instead, more useful clinical information and higher sensitivity and specificity (pooled sensitivities and specificity $90 \%$ and $89 \%$, respectively) to delineate the presence and extent of mandibular involvement in patients with oral cavity cancer, especially in cases of contextual dental artefacts $[11,12]$. For evaluation of precancerous and tumour lesions of larynx, Mannelli et al. expressed the need to integrate different imaging methods, proposing a flow chart that allows to stratify patients and select the most appropriate procedure [13].

Overall, the current practice is not in favour of ${ }^{18} \mathrm{~F}-\mathrm{FDG}$ PET/CT as gold standard for T staging in HNC in exception of cases with suspect mandibular involvement in oral cavity cancer. The preliminary data about ${ }^{18} \mathrm{~F}$-FDG PET/MRI demonstrated high sensitivity and moderate specificity of this technique in the diagnosis of HNC lesions, showing also a better tumour delineation. Further investigations are needed to define the real impact of ${ }^{18} \mathrm{~F}-\mathrm{FDG}$ PET/MRI in HNC and whether the technique can improve the detection rate of occult primary HNC [14].

\subsubsection{Nodal and Distant Metastases Detection}

Lymph nodal involvement is the most important prognostic factor in patients with HNSCC with a significant impact on outcome in terms of disease free survival and overall survival. Lymph nodal (N) metastases occur in approximately $50 \%$ of HNC patients at the time of diagnosis with a consequent survival decrease. An accurate $\mathrm{N}$ staging is therefore a fundamental step. Similarly, the detection of distant metastases at initial staging influences the prognosis avoiding unnecessary radical treatments. Metastases (M) are frequently found in the lungs, followed by the liver and bone.

Several data in the literature confirm an excellent diagnostic accuracy of ${ }^{18} \mathrm{~F}-\mathrm{FDG}$ PET/CT in $\mathrm{N}$ and $\mathrm{M}$ staging. A meta-analysis of Vellayappan et al. assessed the diagnostic accuracy of ${ }^{18} \mathrm{~F}-$ FDG PET/CT for staging nasopharyngeal carcinoma (NPC), showing good accuracy of ${ }^{18} \mathrm{~F}-\mathrm{FDG}$ $\mathrm{PET} / \mathrm{CT}$ for $\mathrm{N}$ staging (pooled sensitivity and specificity were $84 \%$ and $90 \%$, respectively) and for $\mathrm{M}$ staging (pooled sensitivity and specificity were $87 \%$ and $98 \%$, respectively), but not for $\mathrm{T}$ classification [15]. Similarly, Shen et al. confirmed in their meta-analysis an excellent diagnostic performance of ${ }^{18} \mathrm{~F}-\mathrm{FDG}$ PET/CT for detecting lymph node and distant metastases in patients with NPC with a pooled sensitivity and specificity of $89 \%$ and $96 \%$, respectively [16]. Considering only the detection accuracy for regional nodal metastases in HNC before treatment, ${ }^{18} \mathrm{~F}$-FDG PET/CT showed good diagnostic performance $[17,18]$. Moreover, compared with CI, ${ }^{18}$ F-FDG PET/CT may have higher per-necklevel sensitivity [19]. These values are even more significant excluding clinically N0 patients with greater accuracy values for ${ }^{18} \mathrm{~F}-\mathrm{FDG}$ PET/ CT. Several data showed moderate sensitivity of ${ }^{18} \mathrm{~F}-\mathrm{FDG}$ PET/CT for detection of cervical lymph nodal metastases in clinical NO HNSCC patients with absence of significant better diagnostic accuracy compared to $\mathrm{CI}$; conversely, ${ }^{18} \mathrm{~F}-\mathrm{FDG}$ PET/CT has a higher specificity and negative predictive value for the detection of cervical metastatic lymph nodes compared to the other imaging 
modalities in clinical N0 HNSCC [20-22]. Avoiding elective neck dissection is a fundamental step in the diagnostic-therapeutic flow chart of these patients in order to minimize morbidity and health costs. At present elective neck dissection in patients with clinical NO should not be based upon cross-sectional imaging. A combination of $\mathrm{CI}$ and sentinel node biopsy seems to be the preferred staging strategy to reduce the risk of occult metastases in clinical N0 HNSCC [23].

On the other hand, the excellent diagnostic performance of ${ }^{18} \mathrm{~F}-\mathrm{FDG}$ PET/CT for detecting distant metastases is clearly underlined in the literature [24-29]. Xu et al. showed a pooled sensitivity and specificity of $85.7 \%$ and $98.1 \%$, respectively, for ${ }^{18} \mathrm{~F}$-FDG PET/CT, resulting in a significantly better M staging than CI [26]. This was mainly due to the superior diagnostic performance of ${ }^{18} \mathrm{~F}$-FDG PET/CT compared to $\mathrm{CI}$ in detecting bone metastases [27]. In this setting, ${ }^{18}$ F-FDG PET/CT has higher sensitivity compared to bone scintigraphy [28]. On the other hand, for detection of liver metastases ${ }^{18} \mathrm{~F}-\mathrm{FDG}$ $\mathrm{PET} / \mathrm{CT}$ requires further optimization and integration with CI, especially contrast-enhanced CT and MRI [25]. About lung metastases, a metaanalysis demonstrated that ${ }^{18} \mathrm{~F}$-FDG PET/CT is a valuable diagnostic tool for diagnosing lung malignancies in patients with HNSCC [29].

\subsection{Prognostic Value}

The prognostic value of ${ }^{18} \mathrm{~F}$-FDG PET/CT has been widely discussed with controversial results. Relevant limiting factors are the variability and reproducibility of each individual parameter. Overall, maximum standardized uptake value (SUVmax), metabolic tumour volume (MTV) and total lesion glycolysis (TLG) were significant prognostic predictors in patients with HNC [30-36].

No significant correlation was found between metabolic parameters of ${ }^{18} \mathrm{~F}-\mathrm{FDG}$ PET/CT in HNC and human papillomavirus (HPV) status [37]. Furthermore, the semi-quantitative PET/CT parameters were not related to histopathological parameters in HNSCC, as Ki67 and p53 [38].

\subsection{Post-treatment Evaluation}

Relevant applications of ${ }^{18} \mathrm{~F}-\mathrm{FDG}$ PET/CT in $\mathrm{HNC}$ are delineation of the tumour volume for radiation treatment planning, discrimination of post-treatment changes, evaluation of response to multimodality therapy and detection of recurrence.

About radiation therapy planning, Jeong et al. found that ${ }^{18} \mathrm{~F}$-FDG-avid $\mathrm{HNC}$ apparently require 10-30\% more radiation dose than FDG-non-avid tumours, supporting radiotherapy boosts for ${ }^{18}$ F-FDG-avid tumours; prospective studies are still required in this field [39].

The role of intra-therapy and post-therapy ${ }^{18} \mathrm{~F}$ FDG PET/CT in predicting long-term survival outcomes in patients treated for HNC has been widely studied. Sheikhbahaei et al. reported that positive results of intra-therapy or post-therapy ${ }^{18}$ F-FDG PET/CT could significantly predict the 2- and 5-year risk of death or disease progression [40]. The same group confirmed the high diagnostic performance of ${ }^{18} \mathrm{~F}-\mathrm{FDG}$ PET/CT in detecting local, regional and distant recurrences in curatively treated patients with HNC. The pooled sensitivity and specificity of follow-up ${ }^{18} \mathrm{~F}-\mathrm{FDG} \mathrm{PET} / \mathrm{CT}$ for detection of recurrence were $92 \%$ and $87 \%$, respectively [41]. These data support its use in clinical practice as confirmed also by other studies that highlight the high accuracy of ${ }^{18} \mathrm{~F}$-FDG PET/CT performed after the completion of therapy both in NPC and HNSCC before salvage treatment [42-44]. ${ }^{18}$ F-FDG PET/ CT is also superior to MRI in distinguishing recurrent NPC from fibrosis or scar tissue after radiotherapy in irradiated fields with distortion of normal architecture [45]. Treatment-to-time scan remains a debated aspect. Several works have indicated that early ${ }^{18} \mathrm{~F}-\mathrm{FDG} \mathrm{PET} / \mathrm{CT}$ was less accurate than more delayed imaging after therapy, particularly Cheung and coauthors supported the use of ${ }^{18} \mathrm{~F}$-FDG PET/CT more than 12 weeks after radiotherapy with or without chemotherapy for the assessment of residual or recurrent HNC [46]. Recently, Helsen et al. confirmed that ${ }^{18} \mathrm{~F}$ FDG PET/CT performed within 6 months after chemo-radiotherapy in HNSCC patients is the method of choice for ruling out residual/recurrent 
nodal disease reducing the need for therapeutic intervention [47]. Finally, sensitivity and specificity of ${ }^{18} \mathrm{~F}-\mathrm{FDG}$ PET/CT in identifying local failure following curative radiotherapy or surgery for HNSCC were significantly improved when imaging was performed 3 months after end of treatment [48].

\subsection{Carcinoma of Unknown Origin and Incidental Findings}

Several studies have investigated the accuracy of ${ }^{18}$ F-FDG PET/CT to identify carcinoma of unknown origin (CUP) in patients with cervical lymph nodal metastases. Generally, the most common sites of detection include the palatine tonsils and the base of the tongue, with increase of falsenegative results when the primary tumour is small or adjacent to physiological uptake sites. Zhu et al. showed a high sensitivity (97\%) and a moderate specificity (68\%) for the detection of CUP in patients with cervical nodal metastases [49].

Finally, Treglia et al. calculated the pooled prevalence and risk of malignancy of incidental focal ${ }^{18} \mathrm{~F}-\mathrm{FDG}$ uptake in the parotid glands. The pooled prevalence of this finding is about $1 \%$ of all ${ }^{18} \mathrm{~F}-\mathrm{FDG}$ PET/CT. Although these incidental findings are benign in most of the cases, complementary evaluation is needed to exclude malignant lesions or with possible malignant degeneration [50].

\section{References}

1. Bray F, Ferlay J, Soerjomataram I, Siegel RL, Torre LA, Jemal A. Global cancer statistics 2018: GLOBOCAN estimates of incidence and mortality worldwide for 36 cancers in 185 countries. CA Cancer J Clin. 2018;68(6):394-424.

2. Bray F, Ren JS, Masuyer E, Ferlay J. Global estimates of cancer prevalence for 27 sites in the adult population in 2008. Int J Cancer. 2013;132(5):1133-45.

3. Settle K, Posner MR, Schumaker LM, Tan M, Suntharalingam M, Goloubeva O, et al. Racial survival disparity in head and neck cancer results from low prevalence of human papillomavirus infection in black oropharyngeal cancer patients. Cancer Prev Res. 2009;2(9):776-81.
4. Wyss A, Hashibe M, Chuang SC, Lee YC, Zhang ZF, Yu GP, et al. Cigarette, cigar, and pipe smoking and the risk of head and neck cancers: pooled analysis in the International Head and Neck Cancer Epidemiology Consortium. Am J Epidemiol. 2013;178(5):679-90.

5. Rodrigues RS, Bozza FA, Christian PE, Hoffman JM, Butterfield RI, Christensen CR, et al. Comparison of whole-body PET/CT, dedicated high-resolution head and neck PET/CT, and contrast-enhanced CT in preoperative staging of clinically M0 squamous cell carcinoma of the head and neck. J Nucl Med. 2009;50(8):1205-13.

6. Oyen WJ, Marres HA, Kaanders JH. Progress in nuclear medicine procedures in head and neck oncology. Q J Nucl Med Mol Imaging. 2011;55(5):485-6.

7. Connell CA, Corry J, Milner AD, Hogg A, Hicks RJ, Rischin D, et al. Clinical impact of, and prognostic stratification by, F-18 FDG PET/CT in head and neck mucosal squamous cell carcinoma. Head Neck. 2007;29(11):986-95.

8. Rohde M, Dyrvig AK, Johansen J, Sørensen JA, Gerke $\mathrm{O}$, Nielsen AL, et al. 18F-fluoro-deoxy-glucosepositron emission tomography/computed tomography in diagnosis of head and neck squamous cell carcinoma: a systematic review and meta-analysis. Eur J Cancer. 2014;50(13):2271-9.

9. Chen WS, Li JJ, Hong L, Xing ZB, Wang F, Li CQ. Comparison of MRI, CT and 18F-FDG PET/CT in the diagnosis of local and metastatic of nasopharyngeal carcinomas: an updated meta analysis of clinical studies. Am J Transl Res. 2016;8(11):4532-47.

10. Su Z, Duan Z, Pan W, Wu C, Jia Y, Han B, et al. Predicting extracapsular spread of head and neck cancers using different imaging techniques: a systematic review and meta-analysis. Int J Oral Maxillofac Surg. 2016;45(4):413-21.

11. Qiao X, Liu W, Cao Y, Miao C, Yang W, Su N, et al. Performance of different imaging techniques in the diagnosis of head and neck cancer mandibular invasion: a systematic review and meta-analysis. Oral Oncol. 2018;86:150-64.

12. Li C, Sheng S, Men Y, Sun H, Xia H, Li L. Emission computed tomography for the diagnosis of mandibular invasion by head and neck cancers: a systematic review and meta-analysis. J Oral Maxillofac Surg. 2015;73(9):1875.

13. Mannelli G, Cecconi L, Gallo O. Laryngeal preneoplastic lesions and cancer: challenging diagnosis. Qualitative literature review and meta-analysis. Crit Rev Oncol Hematol. 2016;106:64-9.

14. Xiao Y, Chen Y, Shi Y, Wu Z. The value of fluorine-18 fluorodeoxyglucose PET/MRI in the diagnosis of head and neck carcinoma: a meta-analysis. Nucl Med Commun. 2015;36(4):312-8.

15. Vellayappan BA, Soon YY, Earnest A, Zhang Q, Koh WY, Tham IW, et al. Accuracy of (18) F-flurodeoxyglucose-positron emission tomography/ computed tomography in the staging of newly diagnosed nasopharyngeal carcinoma: a systematic review and meta-analysis. Radiol Oncol. 2014;48(4):331-8. 
16. Shen G, Zhang W, Jia Z, Li J, Wang Q, Deng H. Metaanalysis of diagnostic value of 18F-FDG PET or PET/ $\mathrm{CT}$ for detecting lymph node and distant metastases in patients with nasopharyngeal carcinoma. Br J Radiol. 2014;87(1044):20140296.

17. Yongkui L, Jian L, Wanghan, Jingui L. 18FDGPET/CT for the detection of regional nodal metastasis in patients with primary head and neck cancer before treatment: a meta-analysis. Surg Oncol. 2013;22(2):e11-6.

18. Su N, Li C, Shi Z, Yang X. Positron emission tomography/computed tomography for detecting cervical nodule metastases of oral and maxillofacial cancer. Hua Xi Kou Qiang Yi Xue Za Zhi. 2012;30(1):36-9.

19. Sun R, Tang X, Yang Y, Zhang C. (18)FDG-PET/ $\mathrm{CT}$ for the detection of regional nodal metastasis in patients with head and neck cancer: a meta-analysis. Oral Oncol. 2015;51(4):314-20.

20. Kim SJ, Pak K, Kim K. Diagnostic accuracy of F-18 FDG PET or PET/CT for detection of lymph node metastasis in clinically node negative head and neck cancer patients; a systematic review and metaanalysis. Am J Otolaryngol. 2019;40(2):297-305.

21. Li XY, Sun CL, Du XD. The role of ${ }^{18} \mathrm{~F}-\mathrm{FDG}$ PET/ $\mathrm{CT}$ for detecting nodal metastases in $\mathrm{cN} 0$ head neck cancer patients: a meta-analysis. Lin Chung Er Bi Yan Hou Tou Jing Wai Ke Za Zhi. 2018;32(9):700-4.

22. Liao LJ, Lo WC, Hsu WL, Wang CT, Lai MS. Detection of cervical lymph node metastasis in head and neck cancer patients with clinically NO neck-a meta-analysis comparing different imaging modalities. BMC Cancer. 2012;12:236.

23. Liao LJ, Hsu WL, Wang CT, Lo WC, Lai MS. Analysis of sentinel node biopsy combined with other diagnostic tools in staging $\mathrm{cNO}$ head and neck cancer: a diagnostic meta-analysis. Head Neck. 2016;38(4):628-34.

24. Chang MC, Chen JH, Liang JA, Yang KT, Cheng KY, $\mathrm{Kao} \mathrm{CH}$. Accuracy of whole-body FDG-PET and FDG-PET/CT in M staging of nasopharyngeal carcinoma: a systematic review and meta-analysis. Eur J Radiol. 2013;82(2):366-73.

25. Xu G, Li J, Zuo X, Li C. Comparison of whole body positron emission tomography (PET)/PET-computed tomography and conventional anatomic imaging for detecting distant malignancies in patients with head and neck cancer: a meta-analysis. Laryngoscope. 2012;122(9):1974-8.

26. Xu C, Zhang Y, Peng L, Liu X, Li WF, Sun Y, et al. Optimal modality for detecting distant metastasis in primary nasopharyngeal carcinoma during initial staging: a systemic review and meta-analysis of 1774 patients. J Cancer. 2017;8(7):1238-48.

27. Yi X, Fan M, Liu Y, Zhang H, Liu S. 18 FDG PET and PET-CT for the detection of bone metastases in patients with head and neck cancer. A meta-analysis. J Med Imaging Radiat Oncol. 2013;57(6):674-9.

28. Xu C, Zhang R, Zhang H, Zhang Z. Comparison of 18FDG PET/PET-CT and bone scintigraphy for detecting bone metastases in patients with naso- pharyngeal cancer: a meta-analysis. Oncotarget. 2017;8(35):59740-7.

29. Xi K, Xie X, Xi S. Meta-analysis of (18) fluorodeoxyglucose positron emission tomography-CT for diagnosis of lung malignancies in patients with head and neck squamous cell carcinomas. Head Neck. 2015;37(11):1680-4.

30. Li Q, Zhang J, Cheng W, Zhu C, Chen L, Xia F, et al. Prognostic value of maximum standard uptake value, metabolic tumor volume, and total lesion glycolysis of positron emission tomography/computed tomography in patients with nasopharyngeal carcinoma: a systematic review and meta-analysis. Medicine. 2017;96(37):e8084.

31. Pak K, Cheon GJ, Nam HY, Kim SJ, Kang KW, Chung JK, et al. Prognostic value of metabolic tumor volume and total lesion glycolysis in head and neck cancer: a systematic review and meta-analysis. J Nucl Med. 2014;55:884-90.

32. Huang Y, Feng M, He Q, Yin J, Xu P, Jiang Q, et al. Prognostic value of pretreatment 18F-FDG PET-CT for nasopharyngeal carcinoma patients. Medicine. 2017;96(17):e6721.

33. Lin J, Xie G, Liao G, Wang B, Yan M, Li H, et al. Prognostic value of 18F-FDG-PET/CT in patients with nasopharyngeal carcinoma: a systematic review and meta-analysis. Oncotarget. 2017;8(20):33884-96.

34. Zhang B, Geng J, Nie F, Li X. Primary tumor standardized uptake value predicts survival in head and neck squamous cell carcinoma. Oncol Res Treat. 2015;38(1-2):45-8.

35. Bonomo P, Merlotti A, Olmetto E, Bianchi A, Desideri I, Bacigalupo A, et al. What is the prognostic impact of FDG PET in locally advanced head and neck squamous cell carcinoma treated with concomitant chemoradiotherapy? A systematic review and meta-analysis. Eur J Nucl Med Mol Imaging. 2018;45(12):2122-38.

36. Wang L, Bai J, Duan P. Prognostic value of 18 FFDG PET/CT functional parameters in patients with head and neck cancer: a meta-analysis. Nucl Med Commun. 2019;40(4):361-9.

37. Fleming JC, Woo J, Moutasim K, Mellone M, Frampton SJ, Mead A, et al. HPV, tumour metabolism and novel target identification in head and neck squamous cell carcinoma. $\mathrm{Br} \mathrm{J}$ Cancer. 2019;120(3):356-67.

38. Surov A, Meyer HJ, Wienke A. Can imaging parameters provide information regarding histopathology in head and neck squamous cell carcinoma? A metaanalysis. Transl Oncol. 2018;11(2):498-503.

39. Jeong J, Setton JS, Lee NY, Oh JH, Deasy JO. Estimate of the impact of FDG-avidity on the dose required for head and neck radiotherapy local control. Radiother Oncol. 2014;111(3):340-7.

40. Sheikhbahaei S, Ahn SJ, Moriarty E, Kang H, Fakhry C, Subramaniam RM. Intratherapy or posttherapy FDG PET or FDG PET/CT for patients with head and neck cancer: a systematic review and metaanalysis of prognostic studies. AJR Am J Roentgenol. 2015;205(5):1102-13. 
41. Sheikhbahaei S, Taghipour M, Ahmad R, Fakhry C, Kiess AP, Chung CH, et al. Diagnostic accuracy of follow-up FDG PET or PET/CT in patients with head and neck cancer after definitive treatment: a systematic review and meta-analysis. AJR Am J Roentgenol. 2015;205(3):629-39.

42. Zhou H, Shen G, Zhang W, Cai H, Zhou Y, Li L. 18FFDG PET/CT for the diagnosis of residual or recurrent nasopharyngeal carcinoma after radiotherapy: a metaanalysis. J Nucl Med. 2016;57(3):342-7.

43. Shen G, Zhou L, Jia Z, Zhang W, Wang Q, Deng $\mathrm{H}$. Meta-analysis of PET/CT for diagnosis of residual/ recurrent nasopharyngeal carcinoma. Lin Chung Er Bi Yan Hou Tou Jing Wai Ke Za Zhi. 2015;29(1):61-7.

44. Gao S, Li S, Yang X, Tang Q. 18FDG PET-CT for distant metastases in patients with recurrent head and neck cancer after definitive treatment. A metaanalysis. Oral Oncol. 2014;50(3):163-7.

45. Wei J, Pei S, Zhu X. Comparison of 18F-FDG PET/ $\mathrm{CT}$, MRI and SPECT in the diagnosis of local residual/recurrent nasopharyngeal carcinoma: a metaanalysis. Oral Oncol. 2016;52:11-7.

46. Cheung PK, Chin RY, Eslick GD. Detecting residual/ recurrent head neck squamous cell carcinomas using
PET or PET/CT: systematic review and meta-analysis. Otolaryngol Head Neck Surg. 2016;154(3):421-32.

47. Helsen N, Van den Wyngaert T, Carp L, Stroobants $\mathrm{S}$. FDG-PET/CT for treatment response assessment in head and neck squamous cell carcinoma: a systematic review and meta-analysis of diagnostic performance. Eur J Nucl Med Mol Imaging. 2018;45(6):1063-71.

48. Wong ET, Dmytriw AA, Yu E, Waldron J, Lu L, Fazelzad R, et al. 18 F-FDG PET/CT for locoregional surveillance following definitive treatment of head and neck cancer: a meta-analysis of reported studies. Head Neck. 2019;41(2):551-61.

49. Zhu L, Wang N. 18F-fluorodeoxyglucose positron emission tomography-computed tomography as a diagnostic tool in patients with cervical nodal metastases of unknown primary site: a meta-analysis. Surg Oncol. 2013;22(3):190-4.

50. Treglia G, Bertagna F, Sadeghi R, Muoio B, Giovanella L. Prevalence and risk of malignancy of focal incidental uptake detected by fluorine-18fluorodeoxyglucose positron emission tomography in the parotid gland: a meta-analysis. Eur Arch Otorhinolaryngol. 2015;272(12):3617-26.

Open Access This chapter is licensed under the terms of the Creative Commons Attribution 4.0 International License (http://creativecommons.org/licenses/by/4.0/), which permits use, sharing, adaptation, distribution and reproduction in any medium or format, as long as you give appropriate credit to the original author(s) and the source, provide a link to the Creative Commons license and indicate if changes were made.

The images or other third party material in this chapter are included in the chapter's Creative Commons license, unless indicated otherwise in a credit line to the material. If material is not included in the chapter's Creative Commons license and your intended use is not permitted by statutory regulation or exceeds the permitted use, you will need to obtain permission directly from the copyright holder. 